\title{
Simulation-based concept study of the efficiency gain using a hybrid-electric refrigerated vehicle with an electrically operated cooling system for urban freight transport
}

\author{
D. Dvorak, H. Lacher, D. Simic \& T. Bäuml \\ Mobility Department (Electric Drive Technologies), \\ AIT Austrian Institute of Technology GmbH, Austria
}

\begin{abstract}
In the pursuit of higher energy efficiency, reduced usage of fossil fuels and lower emissions in urban areas, hybrid vehicle technologies are a promising basis for the transportation of refrigerated goods. The goal of the project, described in this contribution, is to develop a refrigerated vehicle for the delivery of goods in urban areas and to design an optimized operating strategy based on hybrid electric technology.

The electrically operated cooling system will be powered by the traction battery of the hybrid vehicle. Independent of the vehicle's operating mode, the electric energy is always generated at high efficiency. Even in idle periods, or during stopand-go traffic, full cooling performance can be delivered continuously. The design and optimization will be conducted by a multiphysical simulation of the entire vehicle including all relevant cooling components.

This paper describes the development of a Toyota hybrid vehicle model and the implementation and validation of the operational strategy of the considered vehicle. Efficiency and power of the vehicle are calculated using efficiency maps of the internal combustion engine and the two motor generators. Measured reallife driving cycle data of a company, which distributes fresh organic vegetables and food in Vienna directly to the customer, will be used to compare the performance of the new vehicle concept with ordinary diesel driven refrigerated vehicles.

The proposed hybrid refrigerated vehicle enables significantly higher energy efficiency than the ordinary system. This can be explained by the advantages of a hybrid electric vehicle itself, especially in the setting of urban traffic. Furthermore,
\end{abstract}


the energy generation for the cooling system always works at highest efficiency of the internal combustion engine due to the operating strategy of the hybrid system. The decreased environmental impact and fuel cost savings of the proposed system will be quantified using the developed simulation model.

Keywords: hybrid electric vehicle, urban freight transport, simulation, energy efficiency, driving range.

\section{Introduction}

This paper describes the "HyKüFa" project, which is funded by the Austrian government. The project is currently work in progress and the intermediate results are presented in the following sections.

Currently all refrigerated vehicles are based on diesel engines where an additional cooling compressor is attached to the pulley system of the internal combustion engine. It works with a fixed ratio to the revolutions of the combustion engine. A lot of time during urban driving, the power is taken of at idling or at low torque demand, when the combustion engine runs at low efficiency, thus accounting for higher fuel consumption. In comparison to that, using an electric propelled cooling compressor in a hybrid electric vehicle [1-3], demand and provision of the power can be separated. The compressor can be optimized for a stationary revolution speed and the hybrid electric vehicle produces the electric energy always at the highest possible efficiency or through recuperation. Another big advantage of the hybrid solution is the freedom to drive the cooling system for a certain amount of time also when the car is stopped, e.g. a break or when the driver delivers goods to the customers. Furthermore, the proposed system can be combined with an intelligent routing algorithm in order to achieve an even higher energy efficiency of the entire vehicle $[4,5]$.

This contribution describes the evaluation of possible efficiency gains and fuel savings compared to a conventional refrigerated vehicle by simulation of multiphysical vehicle models. The evaluations will be performed using a Toyota Auris, which uses the Toyota hybrid system (THS) which will be explained in the following section.

\section{Toyota hybrid system}

The information provided in this section has been taken from [3]. Figure 1 shows a schematic overview of the Toyota hybrid transaxle system [3]. It is composed of the following main components:

- internal combustion engine (ICE)

- power split device gear set (PSD)

- motor speed reduction gear set (MSR)

- starter generator (MG1)

- motor generator (MG2) 

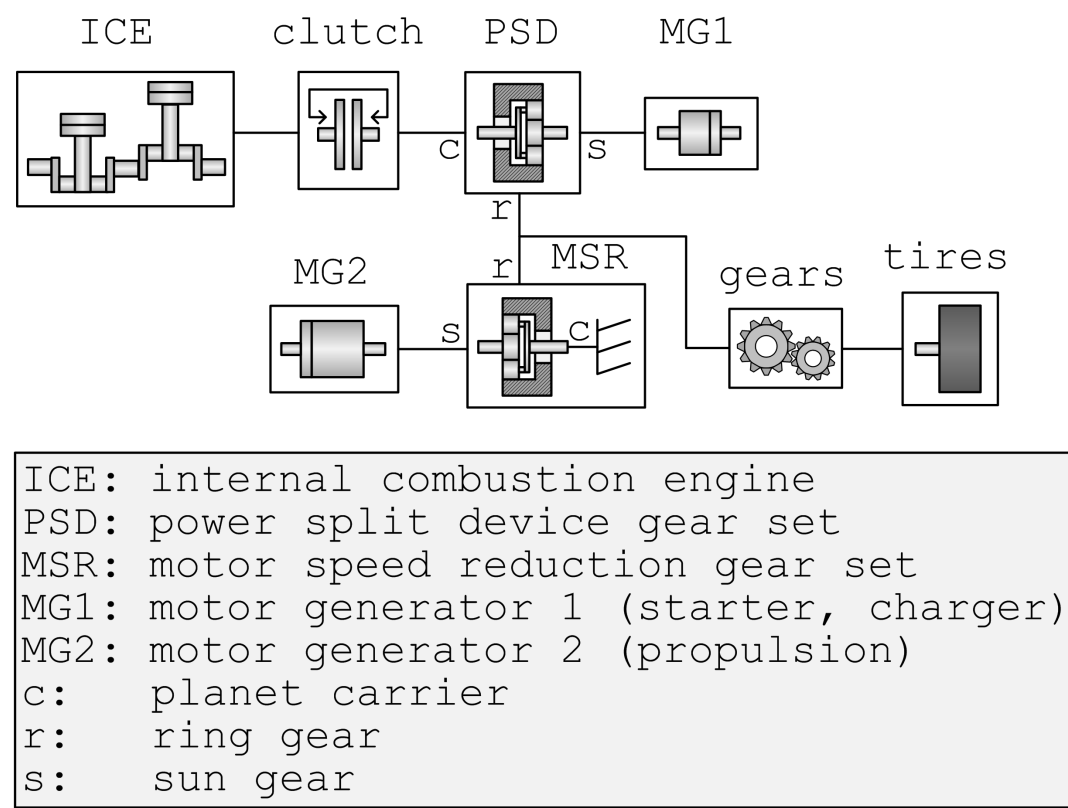

Figure 1: Toyota 3rd generation transaxle system.

The ICE is used for two purposes: propulsion and recharging the battery. The propelled shaft of the ICE is flanged to a clutch which is always closed and used as an overload protection. If the torque on the ICE is too high, the clutch will slip in order to prevent damage to the system.

The other shaft of the clutch is connected to the planet carrier shaft of a planetary gear set. As this gear set is used to split the power of the ICE into charging power for the battery on the one hand and into propulsion power of the vehicle on the other hand, it is also called power split device gear set (PSD).

The MG1 is the smaller one of the two electric machines which are used in the THS. It is flanged to the sun gear shaft of the PSD and used for starting the ICE (i.e. applying a positive torque on the ICE to accelerate it to the required starting speed) and to recuperate the energy provided by the ICE into the battery (i.e. converting the mechanic energy of the ICE into electric energy by applying a negative torque on the ICE).

The MG2 is the more powerful electric machine which is used for acceleration and for recuperative braking (i.e. converting the translational energy of the vehicle into electric energy to charge the battery). This machine is directly flanged to the sun gear shaft of a second gear set, which reduces the speed of MG2 while increasing the torque. Therefore it is called the motor speed reduction gear set (MSR). The planet carrier shaft of the MSR is permanently connected to the car 


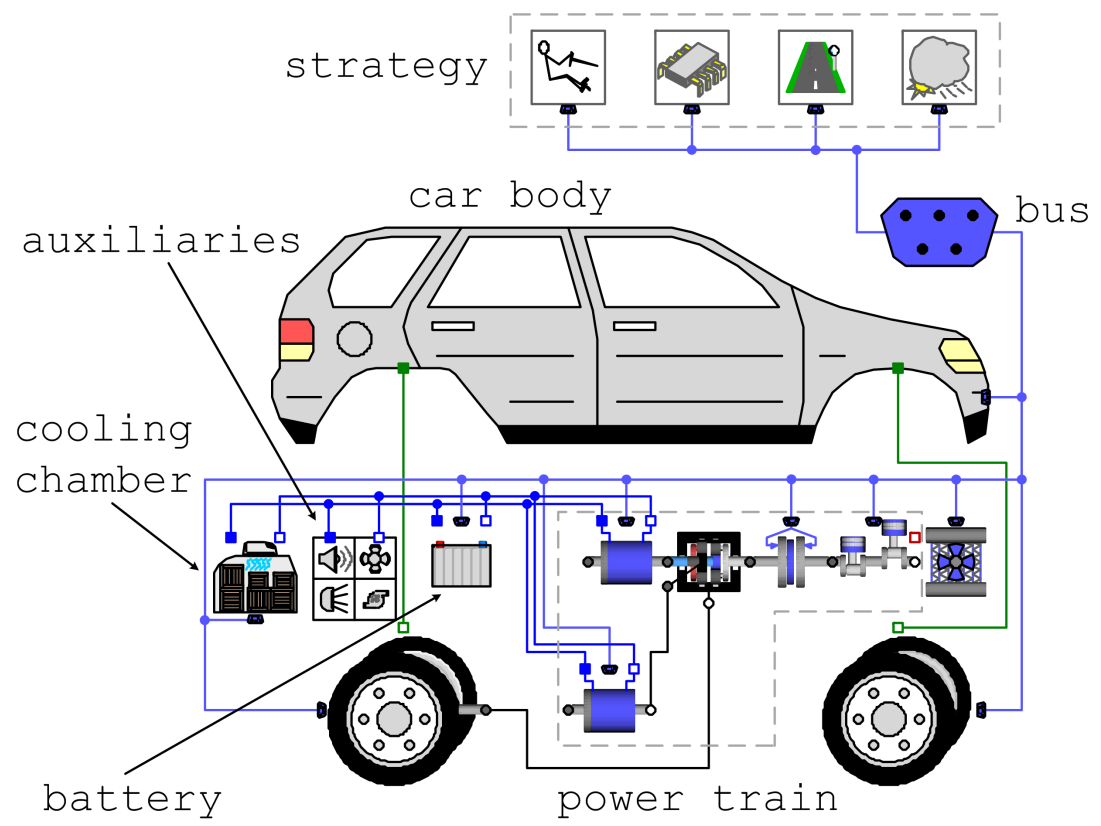

Figure 2: Implementation of the proposed hybrid vehicle for cooling freight transport.

body. The ring gear is directly coupled with the ring gear of the PSD and with the differential gear set for the wheels.

The THS can be operated in five different operating modes. An operation control routine determines the currently most efficient strategy based on multiple input factors. The operation modes include (in hierarchical order):

- charge- / discharge mode

- power assist mode

- lock-up mode

- motor driving mode

- ordinary driving mode

If the battery state of charge (SOC) is outside of a pre-defined interval, the routine enters charge- / discharge mode in order to reach an appropriate SOC level. Otherwise, if the required power output on the ring gear (which is connected to the wheels) of the PSD is greater than the maximum available ICE power, the strategy enters power assist mode. In this mode, both the ICE and the MG2 are used to accelerate the vehicle. If the torque and speed of the ring gear are within a specific range, lock-up mode will be executed. Here, the speed of the MG1 is zero while the vehicle is only propelled by the ICE (in this mode the hybrid system equals a conventional combustion engine vehicle). When the required power and speed of the ring gear are lower than a specific limit, the program enters motor 


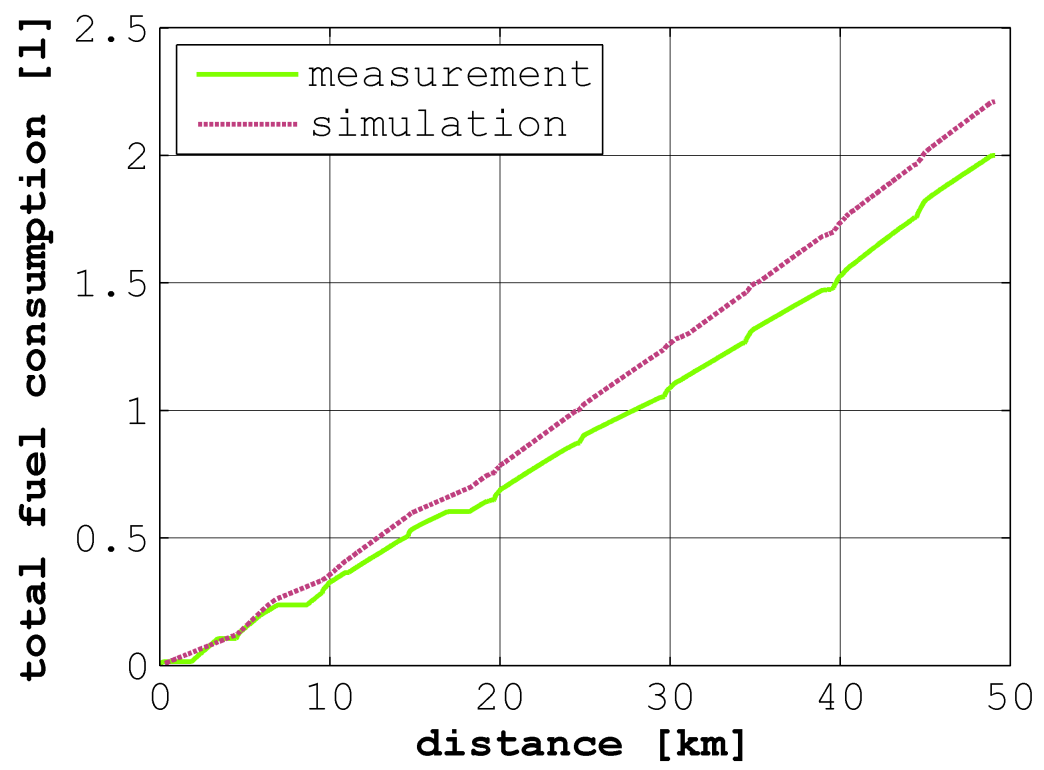

Figure 3: Measured vs. simulated fuel consumption during a real measured driving cycle.

driving mode. In this mode the vehicle is only propelled by the MG2. If none of the abovementioned strategies is applicable, then the ordinary driving mode is executed. Here, the acceleration power is split between the ICE and MG2. Further details about the THS operating modes and operation control routine can be found in [3].

\section{Simulation model}

Based on the patent [3] a simulation model of the hybrid vehicle has been developed and implemented in the modelling language Modelica using the graphical user interface and simulation tool Dymola. Therefore the SmartPowerTrains [6], SmartElectricDrives [6], SmartCooling [7] and ElectricEnergyStorages $[8,9]$ simulation libraries from the Austrian Institute of Technology $\mathrm{GmbH}$ have been used for simulating the vehicle power train, electric machines, cooling system and traction battery, respectively. Figure 2 shows the implementation of the proposed Toyota hybrid vehicle which can be used for cooling freight transport.

The simulation model is capable of reproducing a realistic operating behavior of the hybrid vehicle. All components communicate via a Modelica bus-system 


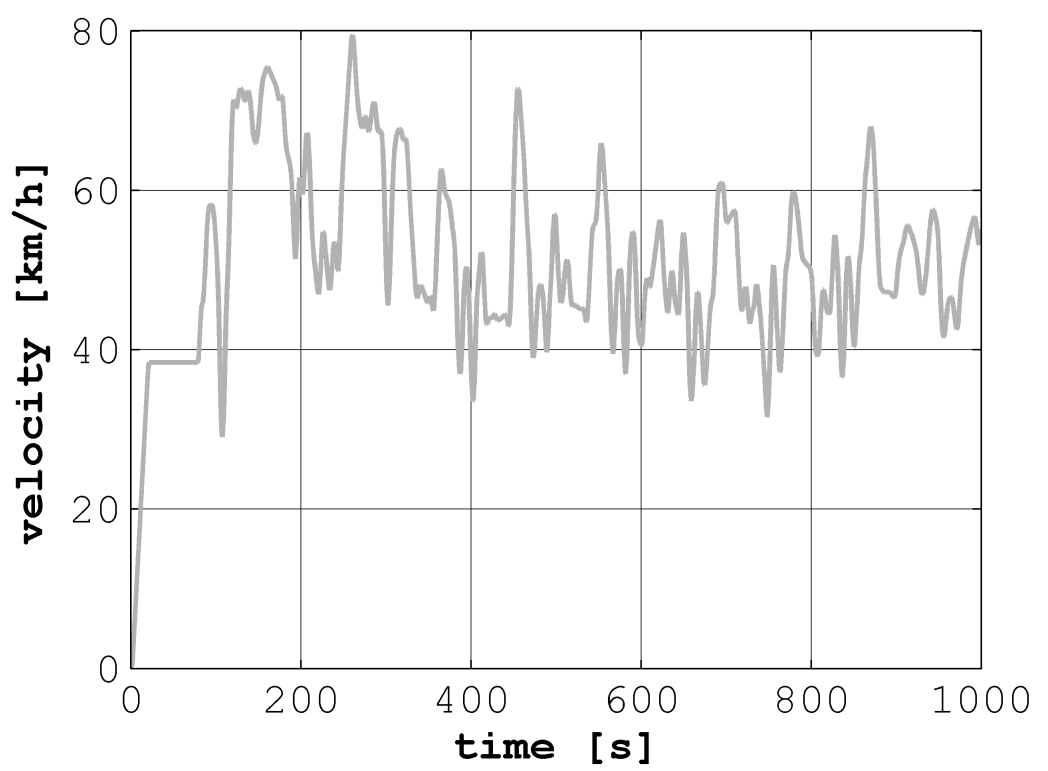

Figure 4: Velocity profile over time in cycle 1.

with each other. The four elements at the top of the model are used to control the strategy and the main behavior of the vehicle. They include a driver model to simulate a real driver behavior based on reference target vehicle velocity, the operating strategy of the vehicle, cycle data including slopes and the weather conditions. The car body model calculates driving resistances while the auxiliaries and the cooling chamber models represent electrical loads such as sound system, head lights, air conditioning and the cooling chamber used for cooling down the freight, respectively. The battery model simulates the operating behavior of the vehicle's traction battery. The power train models represent the components of the THS, which has been described in section 2 .

\section{Model validation}

The developed simulation model was validated by comparing the simulated fuel consumption of the hybrid vehicle with real measured data. The vehicle data was acquired via an On Board Diagnostics II (OBDII) bluetooth adapter. The Android app "Torque" allowed for visualizing and logging all of the available and relevant data directly from the vehicles diagnostic CAN bus. The results of the validation are shown in Figure 3. The graph shows that the deviation between the simulated and measured fuel consumption after about $49 \mathrm{~km}$ of real life cycle is about 0.21 . Hence the model is considered accurately enough for further investigations. 


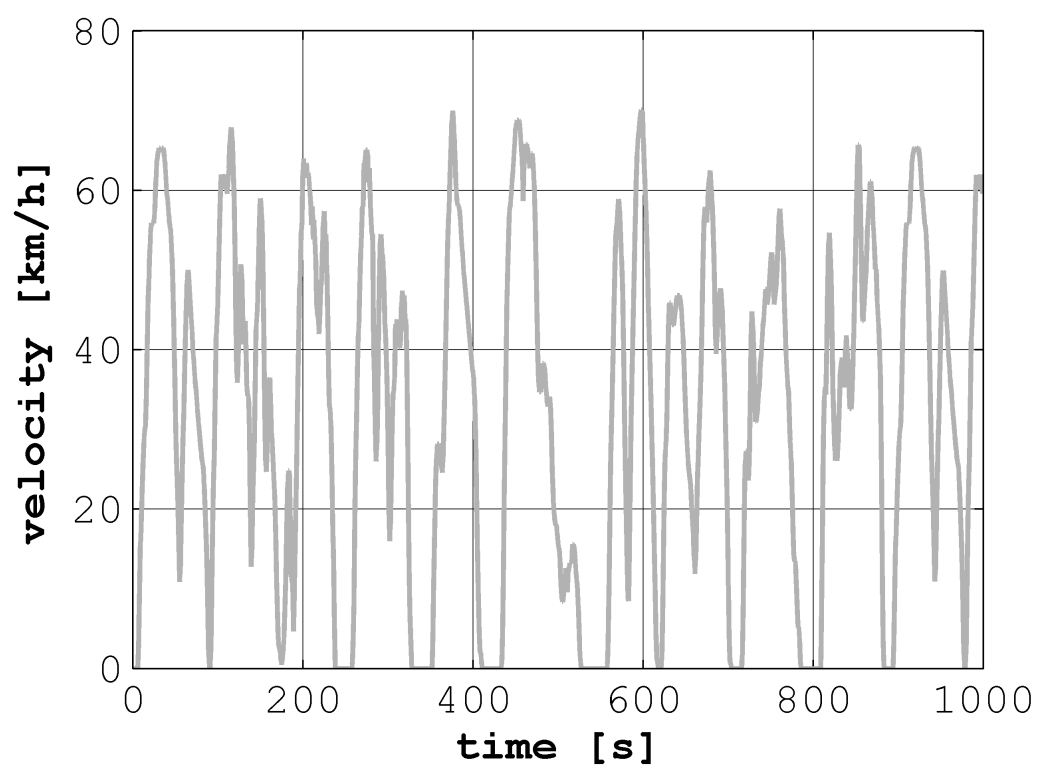

Figure 5: Velocity profile over time in cycle 2.

\section{System comparison}

To evaluate the impact of the cooling system on the energy efficiency of the proposed vehicle, the hybrid system was compared against a common diesel vehicle in two different driving scenarios. The velocity profile over time of cycle 1 is shown in Figure 4 and cycle 2 is shown in Figure 5. Cycle 1 represents 1000 seconds of a real urban driving cycle with low traffic and without intermediate stops and cycle 2 is a 1000 seconds driving profile with multiple stops.

In Figure 6 the efficiency of the four investigated concepts (diesel- and hybrid vehicle with and without cooling system respectively) is plotted for 200-300 s of cycle 2 . The graph shows (e.g. at 240-250 s) that the efficiency of the diesel engine is increased significantly from about $10 \%$ to $25 \%$ in idle mode, when the cooling system is used. When the ICE is used for propulsion, the increase in efficiency through the refrigerant system is by far lower. The efficiency of the hybrid system is not appreciably affected by the use of the cooling system. The deviation between the efficiency of the hybrid system with and without cooling after 280 s occurs only due to a different state of charge level and hence due to a different operating mode at this time interval.

Figure 7 depicts the simulated fuel energy consumption based on cycle 1 of the diesel reference vehicle and the hybrid vehicle with and without cooling chamber, respectively. For converting the volumetric fuel consumption [1] into energy 


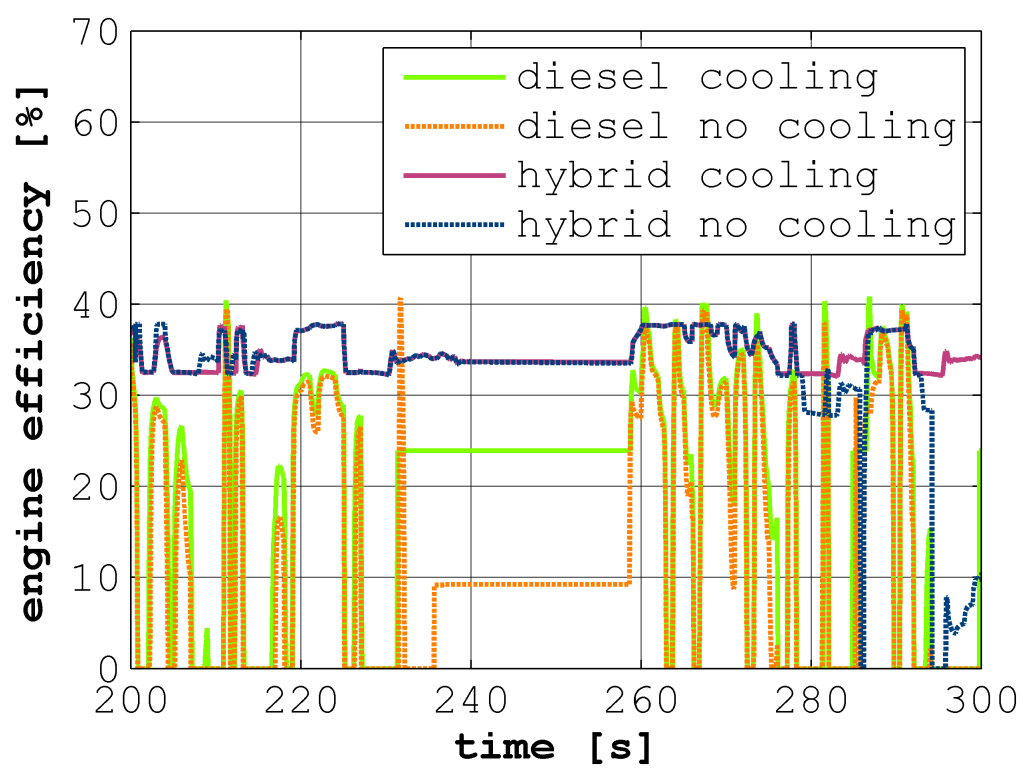

Figure 6: Engine efficiency per time in cycle 2.

Table 1: Total energy and fuel consumption.

\begin{tabular}{|l|l|l|l|}
\hline $\begin{array}{l}\text { Cycle } / \\
\text { Distance }\end{array}$ & Diesel & Hybrid & $\begin{array}{l}\text { Cooling } \\
\text { system }\end{array}$ \\
\hline $1 / 14.18 \mathrm{~km}$ & $7.35 \mathrm{kWh}(0.75 \mathrm{l})$ & $4.97 \mathrm{kWh}(0.57 \mathrm{l})$ & no \\
\hline $1 / 14.18 \mathrm{~km}$ & $9.33 \mathrm{kWh}(0.95 \mathrm{l})$ & $7.32 \mathrm{kWh}(0.84 \mathrm{l})$ & yes \\
\hline $1 / 100 \mathrm{~km}$ & $51.80 \mathrm{kWh}(5.29 \mathrm{l})$ & $35.07 \mathrm{kWh}(4.00 \mathrm{l})$ & no \\
\hline $1 / 100 \mathrm{~km}$ & $65.78 \mathrm{kWh}(6.71 \mathrm{l})$ & $51.63 \mathrm{kWh}(5.89 \mathrm{l})$ & yes \\
\hline $2 / 8.95 \mathrm{~km}$ & $7.57 \mathrm{kWh}(0.77 \mathrm{l})$ & $4.89 \mathrm{kWh}(0.56 \mathrm{l})$ & no \\
\hline $2 / 8.95 \mathrm{~km}$ & $9.21 \mathrm{kWh}(0.94 \mathrm{l})$ & $6.97 \mathrm{kWh}(0.80 \mathrm{l})$ & yes \\
\hline $2 / 100 \mathrm{~km}$ & $84.58 \mathrm{kWh}(8.63 \mathrm{l})$ & $54.67 \mathrm{kWh}(6.241)$ & no \\
\hline $2 / 100 \mathrm{~km}$ & $102.91 \mathrm{kWh}(10.50 \mathrm{l})$ & $77.91 \mathrm{kWh}(8.89 \mathrm{l})$ & yes \\
\hline
\end{tabular}

consumption [kWh], the conversion factors energy $y_{\text {diesel }}=9.800 \frac{\mathrm{kWh}}{\mathrm{l}}$ for diesel and energy gasoline $=8.760 \frac{\mathrm{kWh}}{\mathrm{l}}$ for gasoline have been used. An equivalent evaluation has been performed based on cycle 2 . The results are listed in Table 1. It can be seen that the hybrid system inclusive cooling system consumes still less 


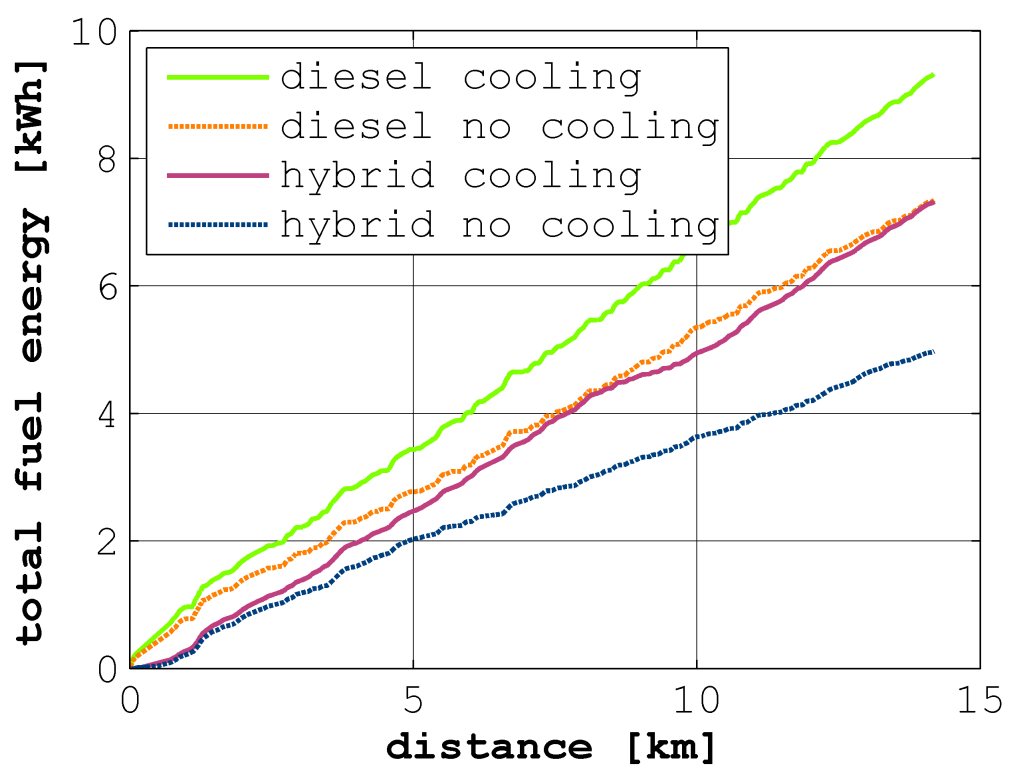

Figure 7: Consumed fuel energy per distance in cycle 1.

energy than the basic diesel vehicle without cooling system (e.g. considering the $14.18 \mathrm{~km}$ in cycle 1 , the hybrid system consumes $7.32 \mathrm{kWh}$ with cooling system whereas the basic diesel vehicle without cooling system consumes $7.35 \mathrm{kWh}$ ).

For further analysis, the additional energy and fuel consumption required for the cooling system of the two vehicle systems along the two driving cycles has been summarized in Table 2. Here the results show that even if the total amount of energy consumed by the cooling system is lower for the hybrid system, the additional energy required for the cooling system is lower for the diesel vehicle. This can be explained by the fact that the compressor for the cooling system is directly connected to the diesel engine and therefore has an efficiency from the ICE to the input shaft of the compressor of almost $100 \%$. In contrast, the energy from the ICE of the hybrid system is reduced by the PSD-, SG- and batteryefficiency until it reaches the electrically driven compressor for the cooling system. Anyway, as already mentioned above, the hybrid system is still the better option when analyzing the total amount of consumed energy and emissions.

\section{Conclusion and outlook}

This contribution presented the preliminary results of the "HyKüFa" project. The benefits and disadvantages of a hybrid vehicle which is used for urban delivery transport have been analyzed and evaluated using a simulative approach. 
Table 2: Additional energy and fuel consumption for cooling system.

\begin{tabular}{|l|l|l|l|}
\hline $\begin{array}{l}\text { Cycle / } \\
\text { Distance }\end{array}$ & Diesel & Hybrid & Difference \\
\hline $1 / 14.18 \mathrm{~km}$ & $1.98 \mathrm{kWh}(0.20 \mathrm{l})$ & $2.35 \mathrm{kWh}(0.27 \mathrm{l})$ & $0.37 \mathrm{kWh}(0.07 \mathrm{l})$ \\
\hline $1 / 100 \mathrm{~km}$ & $13.98 \mathrm{kWh}(1.43 \mathrm{l})$ & $16.55 \mathrm{kWh}(1.89 \mathrm{l})$ & $2.58 \mathrm{kWh}(0.46 \mathrm{l})$ \\
\hline $2 / 8.95 \mathrm{~km}$ & $1.64 \mathrm{kWh}(0.17 \mathrm{l})$ & $2.08 \mathrm{kWh}(0.24 \mathrm{l})$ & $0.44 \mathrm{kWh}(0.07 \mathrm{l})$ \\
\hline $2 / 100 \mathrm{~km}$ & $18.33 \mathrm{kWh}(1.87 \mathrm{l})$ & $23.25 \mathrm{kWh}(2.65 \mathrm{l})$ & $4.92 \mathrm{kWh}(0.8 \mathrm{l})$ \\
\hline
\end{tabular}

The results show that the hybrid vehicle including cooling system has still a lower fuel consumption than a reference diesel vehicle without cooling system. Nevertheless, the additional energy required for cooling down the freight is lower for the diesel vehicle because the efficiency between the output shaft of the ICE and the input shaft of the compressor for the cooling system is higher than for the hybrid vehicle. Anyway, the hybrid system enables significantly more flexibility in positioning the cooling compressor as a direct link to the output shaft of the ICE is not necessary here.

In future steps of the project, the operating strategy will be refined by analyzing and recalculating the limits which are used for operation mode determination. Furthermore, the dependencies and tables which are described in the patent (but not mentioned explicitly) for calculating the target power on the ring gear will be further improved using additional measurement data. Furthermore, the proposed hybrid system can be used in combination with an intelligent routing algorithm $[4,5]$ in order to operate the vehicle even more efficiently (e.g. by using predictive energy management).

\section{References}

[1] Krüger, C., Optimierung von Antriebssträngen fr Hybridfahrzeuge: Konzepte, Lösungsalgorothmen und ausgewählte Implementierung. Master's thesis, Hybride Antriebsstrangtopologien, 2007.

[2] Muta, K., Yamazaki, M. \& Tokieda, J., Development of new-generation hybrid system ths ii - drastic improvement of power performance and fuel economy. Technical report, SAE World Congress, Detroit, 2004.

[3] Nii, Y., Sasaki, S. \& Kotani, T., Power output apparatus and method of controlling the same, 2000.

[4] Prandtstetter, M., Straub, M. \& Puchinger, J., On the way to a multimodal energy-efficient route. IECON, 2013.

[5] Toplak, W., Asamer, J., Straub, M., Dragaschnig, M., Puchinger, J. \& Prandtstetter, M., Rout analysis and planning for urban transportation on basis of floating car data and emission estimates. Transportation Research Board, 2011. 
[6] Giuliani, H., Simic, D., Gragger, J., Kral, C. \& Pirker, F., Optimization of a four wheel drive hybrid vehicle by means of the smartelectricdrives and the smartpowertrains library. 22nd International Battery, Hybrid and Fuel Cell Electric Vehicle Symposium \& Exposition, 2006.

[7] Simic, D., Dvorak, D., Bäuml, T. \& Kapeller, H., Modeling and evaluation of the smartcooling (sc) library for the simulation of the thermal management in automotive applications. European Wolfram Technology Conference, 2014.

[8] Dvorak, D., The electricenergystorages library: Multi-physical battery simulation. International Symposium on E-Mobility \& Energy Management, 2014.

[9] Kapeller, H., Dvorak, D., Bäuml, T., Niklas, C. \& Simic, D., Validation of electric energy storages library based on battery measurements. FISITA World Automotive Congress, 2014. 